\title{
What's New on Quantitative CT Analysis as a Tool to Predict Growth in Persistent Pulmonary Subsolid Nodules? A Literature Review
}

\author{
Andrea Borghesi ${ }^{1, *(\mathbb{D}, \text { Silvia Michelini }}{ }^{2}$, Salvatore Golemi ${ }^{1}$, Alessandra Scrimieri ${ }^{1}$ \\ and Roberto Maroldi ${ }^{1}$ \\ 1 Department of Radiology, University and ASST Spedali Civili of Brescia, Piazzale Spedali Civili 1, \\ 25123 Brescia, Italy; golemisalvatore@gmail.com (S.G.); ascrimieri@alice.it (A.S.); \\ roberto.maroldi@unibs.it (R.M.) \\ 2 Department of Radiology, Fondazione Poliambulanza Istituto Ospedaliero, Via Leonida Bissolati, 57, \\ 25124 Brescia, Italy; silviamichelini2015@gmail.com \\ * Correspondence: andrea.borghesi@unibs.it
}

Received: 27 December 2019; Accepted: 19 January 2020; Published: 21 January 2020

\begin{abstract}
Pulmonary subsolid nodules (SSNs) are observed not infrequently on thin-section chest computed tomography (CT) images. SSNs persisting after a follow-up period of three to six months have a high likelihood of being pre-malignant or malignant lesions. Malignant SSNs usually represent the histologic spectrum of pulmonary adenocarcinomas, and pulmonary adenocarcinomas presenting as SSNs exhibit quite heterogeneous behavior. In fact, while most lesions show an indolent course and may grow very slowly or remain stable for many years, others may exhibit significant growth in a relatively short time. Therefore, it is not yet clear which persistent SSNs should be surgically removed and for how many years stable SSNs should be monitored. In order to solve these two open issues, the use of quantitative analysis has been proposed to define the "tailored" management of persistent SSNs. The main purpose of this review was to summarize recent results about quantitative $\mathrm{CT}$ analysis as a diagnostic tool for predicting the behavior of persistent SSNs. Thus, a literature search was conducted in PubMed/MEDLINE, Scopus, and Web of Science databases to find original articles published from January 2014 to October 2019. The results of the selected studies are presented and compared in a narrative way.
\end{abstract}

Keywords: pulmonary nodule; subsolid nodule; ground-glass nodule; non-solid nodule; part-solid nodule; multidetector computed tomography; computer-assisted image analysis

\section{Introduction}

On thin-section chest computed tomography (CT) images, a subsolid nodule (SSN) is a nuanced nodular opacity that does not completely erase the underlying bronco-vascular structures of the lung [1]. SSNs, also called ground-glass nodules, are observed not infrequently in clinical practice and lung cancer screening programs [2-5], and their incidence is constantly increasing, particularly with the technological improvement of multidetector CT scanners and the broad availability of computer-aided detection software [5-7].

SSNs can be the expression of both benign and malignant lesions, such as inflammation, organizing pneumonia/focal interstitial fibrosis, or pre-invasive and invasive neoplasms [8-10]. SSNs are conventionally divided into non-solid (NSNs) and part-solid nodules (PSNs) according to the absence or presence of an intralesional solid component (Figure 1) [11,12]. PSNs can be further classified into two or three different groups according to the size of the intralesional solid component (Figure 1) [11-13]. 


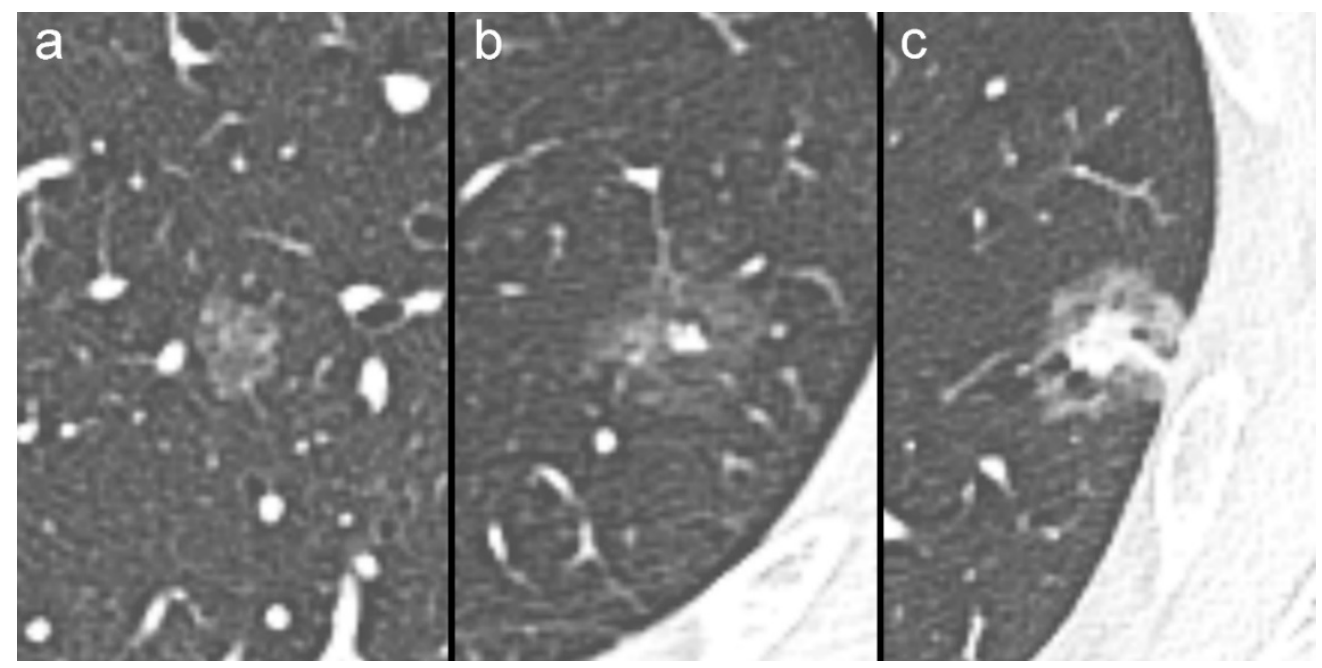

Figure 1. Cropped axial computed tomography (CT) images showing the different subtypes of pulmonary subsolid nodules: (a) non-solid nodule; (b) part-solid nodule with small solid component (less than $6 \mathrm{~mm}$ in diameter); (c) part-solid nodule with a large solid component.

In these different groups of SSNs, the risk of aggressive behavior is strongly associated with the presence and size of the intralesional solid component [11-14]. Therefore, the updated Fleischner Society and Lung CT Screening Reporting and Data System (Lung-RADS) guidelines recommend different management for these different SSN subtypes [11,13].

Regardless of the route of presentation (clinical practice or lung cancer screening), SSNs with a solid component less than $6 \mathrm{~mm}$ in diameter (Figure 1a,b) are considered to have a very low or low probability of becoming aggressive cancer [13]. Therefore, conservative management with CT surveillance is justified for this subtype of SSN [11-14].

On the other hand, SSNs with a solid component greater than 6 or $8 \mathrm{~mm}$ (Figure 1c) are considered suspicious or very suspicious, with a high probability to be or to become aggressive cancers. In this last scenario, a more aggressive approach with additional imaging tests (such as CT at three to six months and/or PET/CT), nonsurgical tissue sampling, and/or surgical resection should be recommended, particularly for SSNs with suspicious morphology, such as irregular or spiculated margins and intralesional bubbly lucencies [11-13].

SSNs that persist after a follow-up period of three to six months have a high likelihood of being pre-malignant or malignant lesions [8-15]. Malignant SSNs usually represent the histologic spectrum of pulmonary adenocarcinoma with lepidic growth pattern, including pre-invasive (adenocarcinoma in situ) and invasive lesions (minimally invasive and lepidic-predominant adenocarcinoma) [16]. Very rarely, malignant SSNs may be the manifestation of primitive pulmonary lymphomas [17] and pulmonary metastases from extrapulmonary malignancies [18,19].

Pulmonary adenocarcinomas presenting as SSNs exhibit quite heterogeneous behavior [20]. While most lesions show an indolent course and may grow very slowly or remain stable for many years (especially NSNs), others (particularly PSNs with a solid component $\geq 8 \mathrm{~mm}$ ) may exhibit a significant growth in size and/or density in a relatively short period of time (few years) [8,11-15]. However, it has been reported that some pulmonary adenocarcinomas presenting as NSNs can grow faster than PSNs, while some pulmonary adenocarcinoma presenting as PSNs can remain unchanged for a long period of time, similarly to NSNs [14,20]. Moreover, it is well known that not all adenocarcinomas presenting as SSNs will become clinically evident cancer in the course of life [8,11-15].

From a clinical point of view, the two main open questions about persistent SSNs still awaiting full resolution are: What SSNs should be surgically resected? How long should a stable or slow-growing SSN be followed? 
With regard to these questions, the most fascinating goal of the radiological evaluation is undoubtedly to extract from radiological images quantitative features that may help in the early discrimination between aggressive and indolent SSNs.

Among the radiological diagnostic methods applied in the thoracic field, CT is the most widely used for quantitative analysis [21]. While the effectiveness of quantitative CT applications for predicting malignancy in solid nodules is well established and widely described in the literature [22,23], those related to SSN growth prediction are much more recent and, therefore, less well-known.

Therefore, the main purpose of this review is to summarize in a narrative way the recently emerged novelties about quantitative $\mathrm{CT}$ analysis as a diagnostic tool for predicting the behavior of persistent SSNs.

\section{Materials and Methods}

\subsection{Literature Search}

A literature search on three main databases (PubMed, Scopus, and Web of Science) was conducted to find relevant articles about the role of quantitative $\mathrm{CT}$ analysis in predicting the growth of persistent SSNs. Different combinations of the following keywords were used for this search: (a) subsolid nodule; (b) non-solid nodule; (c) part-solid nodule; (d) ground-glass nodule; (e) ground-glass opacity; (f) computed tomography; (g) quantitative analysis; (h) computer-assisted; (i) computer-aided; (j) growth; and (k) behavior. The literature search was completed on October 31st, 2019.

\subsection{Selection Criteria}

Only articles in English published from January 2014 to October 2019 that assessed the role of quantitative/computer-assisted CT analysis as a tool to predict the growth/behavior of persistent SSNs were selected and retrieved for this review.

Articles that only used nodule size as a quantitative parameter to predict nodule growth and those without a clear distinction between NSNs and PSNs were excluded. Articles that evaluated the role of quantitative CT analysis only for predicting histological invasiveness of SSNs were also excluded.

In addition, the following types of articles were also excluded from the selection: (a) review articles; (b) case reports/case series; (c) editorials/commentaries; and (d) letters. In order to permit the selection of the largest number of related articles, the references and citations of the retrieved articles were analyzed to find additional relevant studies.

All selected articles were reviewed and analyzed by two radiologists with different levels of experience in chest CT imaging and quantitative analysis (A.B and S.M. who had 15 and 8 years of experience, respectively).

\subsection{Data Extraction}

For each selected article, the following data were collected: (a) study details (first author, year, design); (b) patient characteristics (number, age, gender, smoking habits, oncologic history, country of origin); (c) SSN characteristics (number, subtype, size, location); (d) CT technical parameters (radiation dose, slice thickness); (e) quantitative CT analysis (software, segmentation modality, definition of growth); (f) quantitative CT features/parameters used as predictors of growth/behavior. The results of each study are presented in chronological order and in a narrative manner.

\section{Results}

According to the literature search and selection criteria, only seven original articles met the inclusion criteria and were considered for this review. The main characteristics of the included studies are listed in Tables 1 and 2. 
Table 1. Study details and patient characteristics.

\begin{tabular}{|c|c|c|c|c|c|c|c|c|}
\hline \multirow[b]{2}{*}{ First Author } & \multirow[b]{2}{*}{ Year } & \multirow[b]{2}{*}{ Design } & \multicolumn{5}{|c|}{ Patient Characteristics } & \multirow{2}{*}{ Country } \\
\hline & & & No. & $\begin{array}{l}\text { Age* } \\
\text { (Years) }\end{array}$ & $\begin{array}{l}\text { Gender } \\
\text { (M:F) }\end{array}$ & $\begin{array}{l}\text { Smoking } \\
\text { Habit (\%) }\end{array}$ & $\begin{array}{c}\text { Lung Cancer } \\
\text { History (\%) }\end{array}$ & \\
\hline Eguchi [25] & 2014 & Retrospective & 124 & $64.5 \pm 10.4$ & $37: 87$ & 20.2 & 50.8 & Japan \\
\hline Bak [26] & 2016 & Retrospective & 49 & $58.9 \pm 8.1$ & $26: 23$ & 40.8 & NA & South Korea \\
\hline Shi [28] & 2019 & Retrospective & 59 & $61(40-85)$ & $19: 40$ & 33.9 & 0 & China \\
\hline Borghesi [29] & 2019 & Retrospective & 50 & $65.5 \pm 10.5$ & $24: 26$ & 70.0 & $20.0 \S$ & Italy \\
\hline Qi [30] & 2019 & Retrospective & 110 & $54.3 \pm 9.7$ & $38: 72$ & NA & $9.1^{\wedge}$ & China \\
\hline
\end{tabular}

* Age is presented as mean \pm standard deviation or median (range); + Characteristics of the 63 nodules included in the study; ${ }^{\S} 23 / 50(46 \%)$ patients had an oncologic history (20\% lung and $26 \%$ other cancers); ${ }^{\wedge} 23 / 110(20.9 \%)$ patients had an oncologic history ( $9.1 \%$ lung and $11.8 \%$ other cancers); NA, not available.

Table 2. Subsolid nodule characteristics, technical aspects, and quantitative features.

\begin{tabular}{|c|c|c|c|c|c|c|c|}
\hline \multirow{3}{*}{ First Author } & \multicolumn{4}{|c|}{ Subsolid Nodule Characteristics } & \multicolumn{2}{|c|}{ CT Technical Parameters } & \multirow{3}{*}{$\begin{array}{l}\text { Quantitative CT Feature(s) } \\
\text { Predictive of Growth }\end{array}$} \\
\hline & \multirow{2}{*}{ No. } & \multicolumn{2}{|c|}{ Subtype } & \multirow{2}{*}{ Size * (mm) } & \multirow{2}{*}{ Slice $(\mathrm{mm})$} & \multirow{2}{*}{ X-ray Dose } & \\
\hline & & NSN & PSN & & & & \\
\hline Tamura [24] & 63 & 63 & 0 & $11.4 \pm 4.2$ & 2.0 & SD & Mean CTA \\
\hline Eguchi [25] & $\mathrm{NA}^{\circ}$ & $\mathrm{NA}^{\circ}$ & 0 & $7.4 \pm 2.8$ & 1.25 & $\begin{array}{l}32 \mathrm{LD} \\
92 \mathrm{SD}\end{array}$ & Mean CTA \\
\hline Bak [26] & 54 & 54 & 0 & $11.7 \pm 5.4$ & $2.0-2.5$ & SD & $\begin{array}{c}\text { 97.5th PCTL of CTA } \\
\text { Slope of CTA (from 2.5th to } \\
\text { 97.5thPCTL) }\end{array}$ \\
\hline Sun [27] & 89 & 42 & 47 & $14.3 \S$ & 1.25 & LD & Uniformity^ $^{\wedge}$ \\
\hline Shi [28] & 101 & 101 & 0 & $\begin{array}{c}8.9 \pm 2.6(\mathrm{~S}) \\
14.3 \pm 3.6(\mathrm{G})\end{array}$ & 1.0 & SD & $\begin{array}{l}\text { 3D maximum diameter } \\
\text { Standard deviation of CTA }\end{array}$ \\
\hline Borghesi [29] & 50 & 0 & $50^{+}$ & $11(8.3-13.2)$ & 1.0 & SD & $\begin{array}{l}\text { Area, perimeter, diameter, } \\
\text { LMD, circularity, solidity }\end{array}$ \\
\hline Qi [30] & 110 & 110 & 0 & $8.7 \pm 3.2$ & $1.0-1.25$ & $\mathrm{LD}$ or $\mathrm{SD} \ddagger$ & Diameter, volume, mass \\
\hline
\end{tabular}

NSN, nonsolid nodule; PSN, part-solid nodule; SD, standard dose; LD, low dose; CTA, CT attenuation value; PCTL, percentile; S, stable NSNs; G, growing NSNs; LMD, linear mass density; NA, not available. * Nodule size is

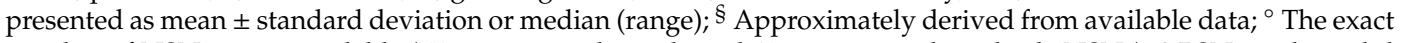
number of NSNs is not available (75 patients with single and 49 patients with multiple NSNs); † PSNs with a solid component $<6 \mathrm{~mm}$; ${ }^{\wedge}$ Only in NSNs. $\ddagger$ The CT protocol was heterogeneous (LD or SD, and unenhanced or enhanced CT scan).

In 2014, Tamura et al. [24] and Eguchi et al. [25] published two independent retrospective studies including a total of 177 patients with single or multiple NSNs. Both studies tested some clinical and quantitative features, such as smoking history, lung cancer history, number of NSNs per patient, NSN diameter, and mean CT attenuation (m-CTA) [24,25]. In both studies, nodule segmentation was performed manually only on the cross-sectional image containing the largest nodule diameter. With regard to the definition of growth, both studies defined nodule growth as an increase in the nodule diameter by $\geq 2 \mathrm{~mm}$ or the emergence of an intralesional solid component [24,25].

In multivariable analysis, these studies found that $\mathrm{m}$-CTA was an independent predictive factor for nodule growth $(p \leq 0.002)[24,25]$. In both studies, the maximum sensitivity and specificity for predicting the growth in NSNs were obtained using a similar density cutoff value (m-CTA of about $-670 \mathrm{UH}$ ). However, while in the paper of Eguchi et al. [25] the values of sensitivity (SE) and specificity (SP) at this cutoff value and the area under the curve (AUC) were reported (SE, 78.1\%; SP, 80.0\%; AUC, 0.81), these data were not available from the paper of Tamura et al. [24].

Among the clinical features, Tamura et al. [24] found that a previous history of lung cancer was the only patient characteristic strongly associated with nodule growth, whereas Eguchi et al. [25] observed that only smoking history was predictive of growth. 
In another retrospective study published in 2016, Bak et al. [26] investigated some quantitative features (such as nodule diameter, volume, mass, and density) in a group of 54 histologically confirmed NSNs (six adenocarcinomas in situ, 16 minimally invasive adenocarcinomas, and 32 invasive adenocarcinomas). Regarding the computerized analysis, the segmentation process was performed manually on cross-sectional images containing the entire nodule; nodule growth, similarly to previous studies, was defined as an increase in diameter by $\geq 2 \mathrm{~mm}$ or the emergence of an internal solid component. In their three-dimensional analysis, the authors found that NSNs with a higher 97.5th percentile CTA value and steeper slope of the increase of CTA values from the 2.5th to the 97.5th percentile exhibited a propensity for higher growth rate and the development of an intralesional solid component. They also found that the combination of these two predictive factors provided an AUC of 0.78. In this study, no statistical comparison was made between patient characteristics or the number of NSNs per patient and nodule growth.

The other four original articles were published in 2019 [27-30]. Two articles, published by Shi et al. [28] and Qi et al. [30], focused exclusively on NSNs. Among the remaining two articles, while the study of Sun et al. [27] included both NSNs and PSNs, the one by Borghesi et al. [29] included only PSNs with a solid component less than $6 \mathrm{~mm}$ and diameter between 6 and $15 \mathrm{~mm}$.

Shi et al. [28] included 59 patients with 101 NSNs. In their sample, the authors assessed several quantitative features (volumetric and histogram parameters) in order to identify the factors predictive of nodule growth. Nodule segmentation was performed in a semiautomatic mode using three-dimensional (3D) open-source software including the entire nodule. In this quantitative analysis, the authors defined growth as an increase in NSN diameter and volume/mass by at least $2 \mathrm{~mm}$ and $30 \%$, respectively.

Based on multivariable analysis, Shi et al. [28] found that only 3D maximum diameter and CTA standard deviation were independent predictors of nodule growth $(p=0.001)$. In particular, the optimal cutoff values were $10.2 \mathrm{~mm}$ (for 3D maximum diameter) and $50 \mathrm{HU}$ (for CTA standard deviation), and the AUC values were 0.896 and 0.813 , respectively [28]. No correlation was observed between clinical features (such as patient age, sex, and smoking habits) or the number of NSNs per patient and nodule growth [28].

Qi et al. included 110 NSNs from 110 patients [30]. In this sample, they evaluated the natural history of persistent NSNs with deep learning-assisted nodule segmentation. For this analysis, some quantitative (nodule diameter, $\mathrm{m}$-CTA, volume and mass) and non-quantitative morphological features (lobulated sign, spiculated sign, vacuole sign, air bronchogram, pleural adhesion and retraction) were considered. Nodule segmentation was performed automatically using the Dr. Wise system based on convolution neural networks [30]. The non-quantitative morphological features were assessed by two radiologists with different experience in chest $\mathrm{CT}$. The authors defined the nodule growth as an increase in nodule volume $\geq 20 \%$ or the emergence of an intralesional solid component. In multivariable analysis, the authors found that initial diameter, volume, and mass were the main quantitative factors predicting nodule growth $(p \leq 0.023)$. Among the non-quantitative morphological features, only the lobulated sign was an independent predictor of growth. No correlation was observed between nodule growth and other characteristics, such as patient age, sex, oncologic history, number of NSNs per patient, and nodule location.

The study of Sun et al. [27] included 86 patients with 89 SSNs (42 NSNs and 47 PSNs). The authors assessed the effectiveness of four quantitative features (m-CTA, entropy, uniformity, and energy) in predicting malignancy and growth trends of SSNs detected during a low-dose CT lung cancer screening program. The nodule segmentation was performed manually using texture analysis software on the cross-sectional images containing the most representative area of the SSNs. The authors defined growth as an increase in SSN volume by at least $20 \%$ and calculated the volume and volume doubling time (DT) of the nodules using commercial CT lung analysis software. With regard to the analysis of the growth trend (performed in 61/89 SSNs), Sun et al. [27] found that only uniformity is useful in predicting growth in NSNs $(p=0.026)$, and NSNs with low uniformity exhibiting faster growth. On 
the other hand, no correlation was observed between PSN growth and quantitative features. In this study, no statistical comparison was made between patient characteristics and nodule growth.

Borghesi et al. [29] included 50 patients with a single PSN and assessed several quantitative features (dimensional, densitometric, and shape parameters) in order to find useful factors for predicting nodule growth. Nodule segmentation was performed manually using an open-source software package on the largest cross-sectional area of each PSN. In their quantitative analysis, the authors defined growth as an increase by more than $11.3 \%$ (i.e., more than the coefficient of repeatability of intraobserver variability) of the linear mass density (LMD), a viable two-dimensional alternative to the mass. Moreover, to determine the nodule growth rate, the authors also calculated the LMD-DT by matching the baseline with the last available follow-up CT. Based on the results obtained in their study, Borghesi et al. [29] found that both dimensional (area, perimeter, diameter, LMD) and shape features (circularity and solidity) were significantly related to nodule growth, and the strongest association was observed with circularity and solidity $(p<0.001)$. Among the clinical features (patient age, sex, smoking habits, oncologic history, emphysema status, and PSN lobe location), only oncologic history (lung or other cancers) was strongly associated with nodule growth $(p=0.007)$.

\section{Discussion}

The progressive improvement in the spatial and temporal resolution of multidetector CT scanners and the increased availability of quantitative imaging methods have led to a significant change in the way CT images are analyzed. The effects of computer-aided diagnosis software on radiologist performance are well known. Therefore, their use in the diagnosis and management of several diseases is constantly expanding.

Among quantitative CT methods, those related to thoracic imaging are the most studied $[20,22,23,31-43]$. In particular, the applications related to the classification and management of lung nodules are the most well-known and are used in both clinical practice and lung cancer screening programs $[20,22,23,31-34]$.

While solid pulmonary nodules are the most common, subsolid nodules are the ones with the highest malignancy rate [44]. Moreover, many authors consider persistent SSNs to represent early-stage adenocarcinoma or its precursor [8-15].

The stepwise progression of a persistent SSN from a preinvasive lesion (adenomatous atypical hyperplasia and adenocarcinoma in situ) to an invasive lesion (lepidic-predominant adenocarcinoma), is quite similar to the multistep progression of colorectal cancer from a premalignant (adenomatous polyp) into a malignant lesion (carcinoma). However, while colorectal adenomas are usually removed during a colonoscopy, pulmonary preinvasive lesions presenting as SSNs require thoracic surgery (video or robotic-assisted). Moreover, the intra-operative localization of SSNs during thoracoscopic surgery is difficult without preoperative marking techniques $[45,46]$. Furthermore, due to the typical indolent course of SSNs and their slow growth rate, it is possible that most SSNs will never become active cancer [8,11-15]. Therefore, it is not yet clear which persistent SSNs should be surgically removed and for how many years stable SSNs should be monitored [8,47-49].

In order to solve these two-open issues, the use of quantitative analysis has been proposed to improve the risk stratification of persistent SSNs and the definition of "tailored" management [50-52].

The appropriate knowledge of which quantitative methods are useful for predicting the aggressiveness of persistent SSNs is crucial in this respect, as their application could affect nodule management and future guidelines.

From this point of view, this review focuses on recent innovations in quantitative $\mathrm{CT}$ analysis applied as a tool to predict the future growth of SSNs.

In our literature search, limited to the last few years (from January 2014 to October 2019), we found only seven original studies, all retrospective, meeting our selection criteria (Tables 1 and 2). All studies but one were conducted on Asian patients, and only one included a European (Italian) cohort. Five papers investigated the role of quantitative analysis in NSNs [24-26,28,30], while one 
included both PSNs and NSNs [27] and the remaining paper considered only PSNs with a solid component $<6 \mathrm{~mm}$ [29].

The results on quantitative CT analysis retrieved from the selected articles were rather heterogeneous because different quantitative features were tested and different scanners and acquisition/reconstruction protocols (different slice thickness and radiation dose) were used for CT analysis (Table 2). Considering these differences and the limited number of articles included in this review, the comparison between the different studies was performed in a narrative manner.

Among the five papers that focused only on NSNs, $2 / 5$ (40\%) of studies found that m-CTA was an independent predictive factor of nodule growth $[24,25]$, whereas the other $3 / 5(60 \%)$ of studies did not confirm this strong association $[26,28,30]$. Among these three studies, two found that other density-related CT features (the 97.5th percentile of CTA, the slope of the CTA values from the 2.5th to the 97.5th percentile, and the CTA standard deviation) could be useful predictors of future nodule change $[26,28]$. On the other hand, the remaining study found that only size-related CT features (diameter, volume, and mass) could be useful predictors of nodule growth; however, in this paper, only m-CTA was tested [29].

In agreement with these studies, even the one that focused on both NSNs and PSNs did not confirm the usefulness of m-CTA in predicting growth [27]. The authors of this study only demonstrated the usefulness of uniformity in the group of NSNs (Table 2) [27], specifically showing that the uniformity of growing NSNs was significantly lower than that of stable NSNs.

Uniformity is a texture feature providing information on the homogeneity vs heterogeneity of the nodules. Similarly, the density-related features found in the study of Bak et al. (i.e., the slope of the CTA values from the 2.5th to the 97.5th percentile) [26] and Shi et al. (i.e., the standard deviation of the CTA) reflect the intralesional heterogeneity of NSNs. Therefore, we can conclude that heterogeneity should be an effective parameter for predicting NSN growth.

To confirm the leading role of heterogeneity in predicting NSN behavior, a promising computerized method of analysis capable of an early discrimination between growing and stable NSNs was tested in a small case series [51]. This method of analysis, performed using commercial software, provides information on the nodule heterogeneity in a very clear and straightforward manner, by creating a colored 3D surface model (named mesh plot) of the density/grayscale values within the NSN [51]. If an NSN has high heterogeneity (i.e., greater tendency to grow), the software will create a mesh plot with irregular surface morphology and several peaks, similar to a mountainous area; on the contrary, for an NSN with high homogeneity (i.e., lower trend to grow), the software will create a mesh plot with regular surface morphology and no peaks, similar to a hilly area [51].

In the remaining paper, which focused only on PSNs with small solid component $(<6 \mathrm{~mm})$ in a group of 50 European (Italian) patients, the authors found that size and shape-related features (circularity and solidity) were useful in predicting growth. Circularity is a dimensionless quantitative feature that provides information about the degree to which a nodule resembles a circle [29]. Solidity is also a dimensionless quantitative feature that measures the overall concavity of a nodule [29]. Based on the results of their study, the authors concluded that PSNs with non-spherical and/or irregular shapes, especially when associated with large size, exhibited a greater tendency to grow.

Compared to the previous literature on persistent SSNs [9], the introduction of a computerized method to assess the shape of SSNs is a real innovation, as it eliminates all the limitations of subjective analysis, thus improving the risk stratification of SSNs.

Regarding clinical features, the comparison between the selected studies is even more difficult, as some data were not available. A strong correlation between clinical features and nodule growth has only been observed in 3/7 (42.9\%) of studies. According to some authors [3,15], Eguchi et al. [25] observed a strong correlation with smoking history. Differently, as reported in other studies $[47,53,54]$ Tamura et al. [24] and Borghesi et al. [29] found that an oncological history (lung or other cancers) was a significant risk factor for growth. 
Our review has three main limitations. First, it was not systematic; however, the search strategy was well defined. Second, the number of selected studies was small; however, the literature search was conducted on the three main databases (PubMed/MEDLINE, Scopus and Web of Science). Third, the limited number of selected studies and the heterogeneity of their results did not allow statistical comparison.

\section{Conclusions}

In conclusion, the results of this literature review can be summarized as follows: (a) quantitative $\mathrm{CT}$ analysis can be a useful tool for predicting SSN growth; (b) the role of m-CTA in predicting the growth of NSNs is controversial, as it has only been observed in two studies; (c) quantitative features reflecting nodule heterogeneity can be effective in predicting NSN growth; (d) circularity and solidity are two innovative and robust quantitative shape-related features for predicting the behavior of PSNs with a solid component $<6 \mathrm{~mm}$; (e) oncologic and/or smoking history could be used in combination with quantitative features to improve the risk stratification of SSNs.

Author Contributions: Conceptualization, A.B.; methodology, A.B.; formal analysis, A.B. and S.M.; investigation, A.B., S.M., S.G., and A.S.; resources, A.B., S.M., A.S., and S.G.; data curation, A.B. and S.M.; writing-original draft, A.B. and S.M.; writing-review and editing, A.B., S.M., A.S., S.G., and R.M.; Project administration, A.B. All authors have read and agreed to the published version of the manuscript.

Funding: This research received no external funding.

Conflicts of Interest: The authors declare no conflict of interest.

\section{References}

1. Hansell, D.M.; Bankier, A.A.; MacMahon, H.; McLoud, T.C.; Muller, N.L.; Remy, J. Fleischner society: Glossary of terms for thoracic imaging. Radiology 2008, 246, 697-722. [CrossRef]

2. National Lung Screening Trial Research Team. Reduced lung-cancer mortality with low-dose computed tomographic screening. N. Engl. J. Med. 2011, 365, 395-409. [CrossRef] [PubMed]

3. Kobayashi, Y.; Sakao, Y.; Deshpande, G.A.; Fukui, T.; Mizuno, T.; Kuroda, H.; Sakakura, N.; Usami, N.; Yatabe, Y.; Mitsudomi, T. The association between baseline clinical-radiological characteristics and growth of pulmonary nodules with ground-glass opacity. Lung Cancer 2014, 83, 61-66. [CrossRef] [PubMed]

4. Yip, R.; Yankelevitz, D.F.; Hu, M.; Li, K.; Xu, D.M.; Jirapatnakul, A.; Henschke, C.I. Lung Cancer Deaths in the National Lung Screening Trial Attributed to Nonsolid Nodules. Radiology 2016, 281, 589-596. [CrossRef] [PubMed]

5. Silva, M.; Prokop, M.; Jacobs, C.; Capretti, G.; Sverzellati, N.; Ciompi, F.; van Ginneken, B.; Schaefer-Prokop, C.M.; Galeone, C.; Marchianò, A.; et al. Long-Term Active Surveillance of Screening Detected Subsolid Nodules is a Safe Strategy to Reduce Overtreatment. J. Thorac. Oncol. 2018, 13, 1454-1463. [CrossRef]

6. Yankelevitz, D.F.; Yip, R.; Smith, J.P.; Liang, M.; Liu, Y.; Xu, D.M.; Salvatore, M.M.; Wolf, A.S.; Flores, R.M.; Henschke, C.I. International Early Lung Cancer Action Program Investigators Group. CT Screening for Lung Cancer: Nonsolid Nodules in Baseline and Annual Repeat Rounds. Radiology 2015, 277, 555-564. [CrossRef]

7. Larici, A.R.; Farchione, A.; Franchi, P.; Ciliberto, M.; Cicchetti, G.; Calandriello, L.; Del Ciello, A.; Bonomo, L. Lung nodules: Size still matters. Eur. Respir. Rev. 2017, 26, 170025. [CrossRef]

8. Kobayashi, Y.; Mitsudomi, T. Management of ground-glass opacities: Should all pulmonary lesions with ground-glass opacity be surgically resected? Transl. Lung Cancer Res. 2013, 2, 354-363.

9. Kim, H.Y.; Shim, Y.M.; Lee, K.S.; Han, J.; Yi, C.A.; Kim, Y.K. Persistent pulmonary nodular ground-glass opacity at thin-section CT: Histopathologic comparisons. Radiology 2007, 245, 267-275. [CrossRef]

10. Raad, R.A.; Suh, J.; Harari, S.; Naidich, D.P.; Shiau, M.; Ko, J.P. Nodule characterization: Subsolid nodules. Radiol. Clin. N. Am. 2014, 52, 47-67. [CrossRef]

11. MacMahon, H.; Naidich, D.P.; Goo, J.M.; Lee, K.S.; Leung, A.N.C.; Mayo, J.R.; Mehta, A.C.; Ohno, Y.; Powell, C.A.; Prokop, M.; et al. Guidelines for Management of Incidental Pulmonary Nodules Detected on CT Images: From the Fleischner Society 2017. Radiology 2017, 284, 228-243. [CrossRef] [PubMed] 
12. Bueno, J.; Landeras, L.; Chung, J.H. Updated Fleischner Society Guidelines for Managing Incidental Pulmonary Nodules: Common Questions and Challenging Scenarios. Radiographics 2018, 38, 1337-1350. [CrossRef] [PubMed]

13. American College of Radiology. Lung CT Screening Reporting and Data System (Lung-RADS) Version 1.1 Assessment Categories (2019 Release). Available online: https://www.acr.org (accessed on 2 October 2019).

14. Song, Y.S.; Park, C.M.; Park, S.J.; Lee, S.M.; Jeon, Y.K.; Goo, J.M. Volume and mass doubling times of persistent pulmonary subsolid nodules detected in patients without known malignancy. Radiology 2014, 273, $276-284$. [CrossRef] [PubMed]

15. Kobayashi, Y.; Ambrogio, C.; Mitsudomi, T. Ground-glass nodules of the lung in never-smokers and smokers: Clinical and genetic insights. Transl. Lung Cancer Res. 2018, 7, 487-497. [CrossRef]

16. Hutchinson, B.D.; Moreira, A.L.; Ko, J.P. Spectrum of Subsolid Pulmonary Nodules and Overdiagnosis. Semin Roentgenol. 2017, 52, 143-155. [CrossRef] [PubMed]

17. Albano, D.; Borghesi, A.; Bosio, G.; Bertoli, M.; Maroldi, R.; Giubbini, R.; Bertagna, F. Pulmonary mucosa-associated lymphoid tissue lymphoma: (18)F-FDG PET/CT and CT findings in 28 patients. Br. J. Radiol. 2017, 90, 20170311. [CrossRef]

18. Borghesi, A.; Tironi, A.; Michelini, S.; Scrimieri, A.; Benetti, D.; Maroldi, R. Two synchronous lung metastases from malignant melanoma: The same patient but different morphological patterns. Eur. J. Radiol. Open 2019, 6, 287-290. [CrossRef]

19. Borghesi, A.; Bercich, L.; Michelini, S.; Bertagna, F.; Scrimieri, A.; Maroldi, R. Pulmonary metastases from malignant epithelioid schwannoma of the arm presenting as fast-growing subsolid nodules: Report of an unusual case. Eur. J. Radiol. Open 2019, 6, 307-314. [CrossRef]

20. Borghesi, A.; Farina, D.; Michelini, S.; Ferrari, M.; Benetti, D.; Fisogni, S.; Tironi, A.; Maroldi, R. Pulmonary adenocarcinomas presenting as ground-glass opacities on multidetector CT: Three-dimensional computer-assisted analysis of growth pattern and doubling time. Diagn. Interv. Radiol. 2016, 22, 525-533. [CrossRef]

21. Papapietro, V.R.; Milanese, G.; Borghesi, A.; Sverzellati, N.; Silva, M. Look around your target: A new approach to early diagnosis of lung cancer. Ann. Transl. Med. 2018, 6, S77. [CrossRef]

22. Borghesi, A.; Michelini, S.; Nocivelli, G.; Silva, M.; Scrimieri, A.; Pezzotti, S.; Maroldi, R.; Farina, D. Solid Indeterminate Pulmonary Nodules Less Than or Equal to $250 \mathrm{~mm} 3$ : Application of the Updated Fleischner Society Guidelines in Clinical Practice. Radiol. Res. Pract. 2019, 2019, 7218258. [CrossRef] [PubMed]

23. Borghesi, A.; Michelini, S.; Scrimieri, A.; Golemi, S.; Maroldi, R. Solid Indeterminate Pulmonary Nodules of Less Than 300 mm3: Application of Different Volume Doubling Time Cut-offs in Clinical Practice. Diagnostics 2019, 9, 62. [CrossRef] [PubMed]

24. Tamura, M.; Shimizu, Y.; Yamamoto, T.; Yoshikawa, J.; Hashizume, Y. Predictive value of one-dimensional mean computed tomography value of ground-glass opacity on high-resolution images for the possibility of future change. J. Thorac. Oncol. 2014, 9, 469-472. [CrossRef] [PubMed]

25. Eguchi, T.; Kondo, R.; Kawakami, S.; Matsushita, M.; Yoshizawa, A.; Hara, D.; Matsuoka, S.; Takeda, T.; Miura, K.; Agatsuma, H.; et al. Computed tomography attenuation predicts the growth of pure ground-glass nodules. Lung Cancer 2014, 84, 242-247. [CrossRef] [PubMed]

26. Bak, S.H.; Lee, H.Y.; Kim, J.H.; Um, S.W.; Kwon, O.J.; Han, J.; Kim, H.K.; Kim, J.; Lee, K.S. Quantitative CT Scanning Analysis of Pure Ground-Glass Opacity Nodules Predicts Further CT Scanning Change. Chest 2016, 149, 180-191. [CrossRef]

27. Sun, Q.; Huang, Y.; Wang, J.; Zhao, S.; Zhang, L.; Tang, W.; Wu, N. Applying CT texture analysis to determine the prognostic value of subsolid nodules detected during low-dose CT screening. Clin. Radiol. 2019, 74, 59-66. [CrossRef]

28. Shi, Z.; Deng, J.; She, Y.; Zhang, L.; Ren, Y.; Sun, W.; Su, H.; Dai, C.; Jiang, G.; Sun, X.; et al. Quantitative features can predict further growth of persistent pure ground-glass nodule. Quant. Imaging Med. Surg. 2019, 9, 283-291. [CrossRef]

29. Borghesi, A.; Scrimieri, A.; Michelini, S.; Calandra, G.; Golemi, S.; Tironi, A.; Maroldi, R. Quantitative CT Analysis for Predicting the Behavior of Part-Solid Nodules with Solid Components Less than 6 mm: Size, Density and Shape Descriptors. Appl. Sci. 2019, 9, 3428. [CrossRef] 
30. Qi, L.L.; Wu, B.T.; Tang, W.; Zhou, L.N.; Huang, Y.; Zhao, S.J.; Liu, L.; Li, M.; Zhang, L.; Feng, S.C.; et al. Long-term follow-up of persistent pulmonary pure ground-glass nodules with deep learning-assisted nodule segmentation. Eur. Radiol. 2019, 30, 744-755. [CrossRef]

31. Goo, J.M. A computer-aided diagnosis for evaluating lung nodules on chest CT: The current status and perspective. Korean J. Radio.l 2011, 12, 145-155. [CrossRef]

32. Devaraj, A.; van Ginneken, B.; Nair, A.; Baldwin, D. Use of Volumetry for Lung Nodule Management: Theory and Practice. Radiology 2017, 284, 630-644. [CrossRef]

33. Nishio, M.; Sugiyama, O.; Yakami, M.; Ueno, S.; Kubo, T.; Kuroda, T.; Togashi, K. Computer-aided diagnosis of lung nodule classification between benign nodule, primary lung cancer, and metastatic lung cancer at different image size using deep convolutional neural network with transfer learning. PLoS ONE 2018, 13, e0200721. [CrossRef] [PubMed]

34. Huang, P.; Park, S.; Yan, R.; Lee, J.; Chu, L.C.; Lin, C.T.; Hussien, A.; Rathmell, J.; Thomas, B.; Chen, C.; et al. Added Value of Computer-aided CT Image Features for Early Lung Cancer Diagnosis with Small Pulmonary Nodules: A Matched Case-Control Study. Radiology 2018, 286, 286-295. [CrossRef] [PubMed]

35. Thawani, R.; McLane, M.; Beig, N.; Ghose, S.; Prasanna, P.; Velcheti, V.; Madabhushi, A. Radiomics and radiogenomics in lung cancer: A review for the clinician. Lung Cancer 2018, 115, 34-41. [CrossRef] [PubMed]

36. Ravanelli, M.; Agazzi, G.M.; Ganeshan, B.; Roca, E.; Tononcelli, E.; Bettoni, V.; Caprioli, A.; Borghesi, A.; Berruti, A.; Maroldi, R.; et al. CT texture analysis as predictive factor in metastatic lung adenocarcinoma treated with tyrosine kinase inhibitors (TKIs). Eur. J. Radiol. 2018, 109, 130-135. [CrossRef] [PubMed]

37. Starkov, P.; Aguilera, T.A.; Golden, D.I.; Shultz, D.B.; Trakul, N.; Maxim, P.G.; Le, Q.T.; Loo, B.W.; Diehn, M.; Depeursinge, A.; et al. The use of texture-based radiomics CT analysis to predict outcomes in early-stage non-small cell lung cancer treated with stereotactic ablative radiotherapy. Br. J. Radiol. 2019, 92, 20180228. [CrossRef] [PubMed]

38. Silva, M.; Milanese, G.; Seletti, V.; Ariani, A.; Sverzellati, N. Pulmonary quantitative CT imaging in focal and diffuse disease: Current research and clinical applications. Br. J. Radiol. 2018, 91, 20170644. [CrossRef]

39. Kirby, M.; van Beek, E.J.R.; Seo, J.B.; Biederer, J.; Nakano, Y.; Coxson, H.O.; Parraga, G. Management of COPD: Is there a role for quantitative imaging? Eur. J. Radiol. 2017, 86, 335-342. [CrossRef]

40. Gawlitza, J.; Sturm, T.; Spohrer, K.; Henzler, T.; Akin, I.; Schönberg, S.; Borggrefe, M.; Haubenreisser, H.; Trinkmann, F. Predicting Pulmonary Function Testing from Quantified Computed Tomography Using Machine Learning Algorithms in Patients with COPD. Diagnostics 2019, 9, 33. [CrossRef]

41. Tantucci, C.; Bottone, D.; Borghesi, A.; Guerini, M.; Quadri, F.; Pini, L. Methods for Measuring Lung Volumes: Is There a Better One? Respiration 2016, 91, 273-280. [CrossRef]

42. Chen, A.; Karwoski, R.A.; Gierada, D.S.; Bartholmai, B.J.; Koo, C.W. Quantitative CT Analysis of Diffuse Lung Disease. Radiographics 2019, 29, 190099. [CrossRef] [PubMed]

43. Castillo-Saldana, D.; Hague, C.J.; Coxson, H.O.; Ryerson, C.J. Using Quantitative Computed Tomographic Imaging to Understand Chronic Obstructive Pulmonary Disease and Fibrotic Interstitial Lung Disease: State of the Art and Future Directions. J. Thorac Imaging 2019, 7. [CrossRef] [PubMed]

44. Van't Westeinde, S.C.; de Koning, H.J.; Xu, D.M.; Hoogsteden, H.C.; van Klaveren, R.J. How to deal with incidentally detected pulmonary nodules less than $10 \mathrm{~mm}$ in size on CT in a healthy person. Lung Cancer 2008, 60, 151-159. [CrossRef] [PubMed]

45. Kim, H.; Park, C.M.; Koh, J.M.; Lee, S.M.; Goo, J.M. Pulmonary subsolid nodules: What radiologists need to know about the imaging features and management strategy. Diagn. Interv. Radiol. 2014, 20, 47-57. [CrossRef] [PubMed]

46. Abbas, A.; Kadakia, S.; Ambur, V.; Muro, K.; Kaiser, L. Intraoperative electromagnetic navigational bronchoscopic localization of small, deep, or subsolid pulmonary nodules. J. Thorac. Cardiovasc. Surg. 2017, 153, 1581-1590. [CrossRef]

47. Lee, H.W.; Jin, K.N.; Lee, J.K.; Kim, D.K.; Chung, H.S.; Heo, E.Y.; Choi, S.H. Long-Term Follow-Up of Ground-Glass Nodules After 5 Years of Stability. J. Thorac. Oncol. 2019, 14, 1370-1377. [CrossRef]

48. Tang, E.K.; Chen, C.S.; Wu, C.C.; Wu, M.T.; Yang, T.L.; Liang, H.L.; Hsu, H.T.; Wu, F.Z. Natural History of Persistent Pulmonary Subsolid Nodules: Long-Term Observation of Different Interval Growth. Heart Lung Circ. 2019, 28, 1747-1754. [CrossRef]

49. Hwang, E.J.; Park, C.M. Persistent pulmonary subsolid nodules: How long should they be observed until clinically relevant growth occurs? J. Thorac. Dis. 2019, 11, S1408-S1411. [CrossRef] 
50. Nemec, U.; Heidinger, B.H.; Anderson, K.R.; Westmore, M.S.; VanderLaan, P.A.; Bankier, A.A. Software-based risk stratification of pulmonary adenocarcinomas manifesting as pure ground glass nodules on computed tomography. Eur. Radiol. 2018, 28, 235-242. [CrossRef]

51. Borghesi, A.; Michelini, S.; Bertagna, F.; Scrimieri, A.; Pezzotti, S.; Maroldi, R. Hilly or mountainous surface: A new CT feature to predict the behavior of pure ground glass nodules? Eur. J. Radiol. Open 2018, 5, 177-182. [CrossRef]

52. Aoki, T. Predicting factors of ground-glass lung nodule for growth. J. Thorac. Dis. 2018, 10, S3927-S3929. [CrossRef] [PubMed]

53. Lee, J.H.; Park, C.M.; Lee, S.M.; Kim, H.; McAdams, H.P.; Goo, J.M. Persistent pulmonary subsolid nodules with solid portions of $5 \mathrm{~mm}$ or smaller: Their natural course and predictors of interval growth. Eur. Radiol. 2016, 26, 1529-1537. [CrossRef] [PubMed]

54. Cho, J.; Kim, E.S.; Kim, S.J.; Lee, Y.J.; Park, J.S.; Cho, Y.J.; Yoon, H.I.; Lee, J.H.; Lee, C.T. Long-Term Follow-up of Small Pulmonary Ground-Glass Nodules Stable for 3 Years: Implications of the Proper Follow-up Period and Risk Factors for Subsequent Growth. J. Thorac. Oncol. 2016, 11, 1453-1459. [CrossRef] [PubMed]

(C) 2020 by the authors. Licensee MDPI, Basel, Switzerland. This article is an open access article distributed under the terms and conditions of the Creative Commons Attribution (CC BY) license (http://creativecommons.org/licenses/by/4.0/). 